\title{
Water modulates the lamellar structure and interlayer correlation of poly(perfluorooctyl acrylate) films: a specular and off-specular neutron scattering study
}

\author{
Akihisa Yamamoto ${ }^{1} \cdot$ Yuji Higaki $\mathbb{D}^{2,7} \cdot$ Judith $^{\text {Thoma }}{ }^{3} \cdot$ Esther Kimmle $^{3} \cdot$ Ryohei Ishige $\mathbb{D}^{4} \cdot$ Bruno Demé $^{5}$. \\ Atsushi Takahara ${ }^{2,6} \cdot$ Motomu Tanaka ${ }^{10}{ }^{1,3}$
}

Received: 6 June 2021 / Revised: 13 July 2021 / Accepted: 11 August 2021 / Published online: 27 September 2021

(c) The Author(s) 2021. This article is published with open access

\begin{abstract}
Comb-like polymers with pendant-like perfluorocarbon side chains self-assemble into smectic lamellae and have been extensively used as water-repellent, hydrophobic coating materials characterized by large water contact angles $\left(\theta>120^{\circ}\right)$. As poly(perfluorooctyl acrylate) films are "apparently hydrophobic" $\left(\theta>120^{\circ}\right)$, the interaction of such materials and water molecules has been largely overlooked. To unravel the molecular-level interactions between water and apparently hydrophobic polymers, specular and off-specular neutron scattering experiments were conducted at defined osmotic pressure $\Pi_{\mathrm{H} 2 \mathrm{O}}$. The poly $\left\{2-[(\right.$ perfluorooctylethyl)carbamate $]$ ethyl $\}$ acrylate $\left(\mathrm{PFAUr}-\mathrm{C}_{8}\right)$, which had a carbamate linker, transitioned to another lamellar phase at $89^{\circ} \mathrm{C}$. At $T=25^{\circ} \mathrm{C}$; the lamellar periodicity of PFAUr- $\mathrm{C}_{8}$ slightly increased with decreasing osmotic pressure, while the vertical correlation length increased. However, the poly[(perfluorooctyl)ethyl] acrylate (PFA- $\left.\mathrm{C}_{8}\right)$ that did not contain a carbamate linker directly transitioned to a disordered phase at $84{ }^{\circ} \mathrm{C}$. The lamellar periodicity of PFA$\mathrm{C}_{8}$ was largely independent of the osmotic pressure, suggesting that PFA- $\mathrm{C}_{8}$ was poorly hydrated. Remarkably, the vertical correlation length decreased with decreasing osmotic pressure. Because hydration facilitated by the linker modulated the smectic lamellae of the poly(perfluoroalkyl acrylate), water molecules could be used to optimize the self-assembly of apparently hydrophobic liquid crystalline polymers.
\end{abstract}

\section{Introduction}

Fluorocarbons and hydrocarbons possess distinct structural and physicochemical properties [1,2]. The cross-sectional area of fluorocarbons $\left(27-30 \AA^{2}\right)$ is larger than that of

Supplementary information The online version contains supplementary material available at https://doi.org/10.1038/s41428021-00555-2.

Atsushi Takahara

takahara.atsushi.150@m.kyushu-u.ac.jp

$\triangle$ Motomu Tanaka

tanaka@uni-heidelberg.de

1 Center for Integrative Medicine and Physics, Institute for Advanced Study, Kyoto University, Kyoto 606-8501, Japan

2 Institute for Materials Chemistry and Engineering, Kyushu University, Fukuoka 819-0395, Japan

3 Physical Chemistry of Biosystems, Institute of Physical Chemistry, Heidelberg University, D69120 Heidelberg, Germany hydrocarbons (18-21 $\left.\AA^{2}\right)$. Because of the large steric requirements of fluorine, fluorocarbons adopt a helical conformation and form a rigid, rod-like chain [3]. The cohesion between fluorocarbon chains is weaker than that of their hydrogenated analogs because the polarizability of fluorine is lower than that of hydrogen. Because fluorocarbon chains are both hydrophobic and oleophobic [1], linearly connected fluorocarbon and hydrocarbon chains are amphiphilic. These molecules spread at the air/water

4 Department of Chemical Science and Engineering, School of Materials and Chemical Technology, Tokyo Institute of Technology, Tokyo 152-8552, Japan

5 Institut Laue-Langevin, 6 rue Jules Horowitz, F38042 Grenoble, Cedex 9, France

6 Research Center for Negative Emission Technology, Kyushu University, Fukuoka 819-0395, Japan

7 Present address: Department of Integrated Science and Technology, Faculty of Science and Technology, Oita University, Oita 8701192, Japan 


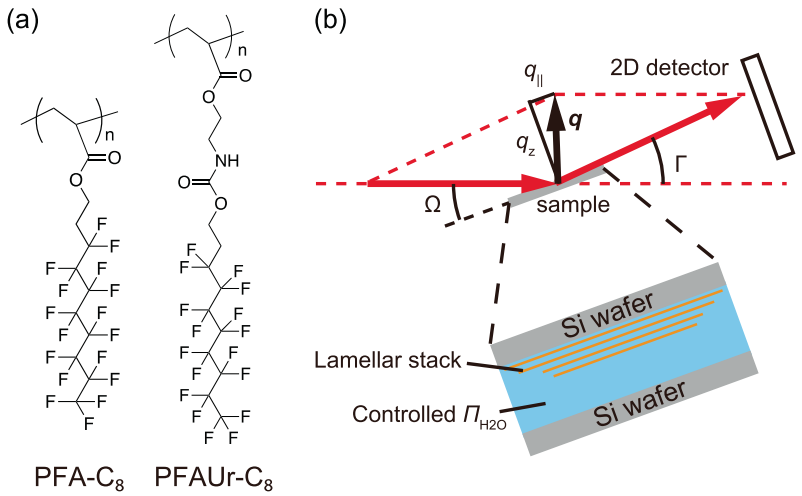

Fig. 1 a Chemical structures of polyacrylate polymers with perfluorooctyl side chains: PFA- $\mathrm{C}_{8}$ and PFAUr- $\mathrm{C}_{8}$. b Schematic illustration of experimental setup

interface to form a monolayer comprising highly monodisperse, disk-like domains that form ordered hexagonal lattices $[4,5]$.

Linear polymer chains functionalized with pendant-like semifluorinated side chains have been extensively used as coating materials for highly hydrophobic surfaces with very low surface energy due to the presence of $-\mathrm{CF}_{3}$ terminal groups [6-10]. Recent studies have demonstrated that fluorocarbon side chains act as mesogens, which facilitate the formation of lamellar structures with lateral orders that depend on the number of fluorinated carbons [11-13], the rigidity of the backbones $[14,15]$, the linker type between the side chains and backbones [9, 16-18], and the $\alpha$ substituents $[19,20]$. Although surface hydrophobicity is routinely assessed by measuring water contact angles, the influence of surrounding water molecules on the structure and physical properties of comb-like fluoropolymers is largely unknown.

In this study, we investigated the effects of hydrating water molecules on the structural order and mechanical properties of polyacrylates coupled to perfluorooctyl side chains via two different linkers (Fig. 1a) by specular and off-specular neutron scattering under a controlled relative humidity (R.H.) as well as in bulk water (Fig. 1b) [21]. This technique was applied to various lamellar structures made by phospholipids and glycolipids [22-24]. In a continuum approximation, if the total free energy of membrane stacks can be described by the discrete smectic Hamiltonian [25], the full calculation of the twodimensional scattering signals can be used to determine not only the changes in the periodicity but also the two principal mechanical parameters of smectic membranes: The compression modulus and bending rigidity. To highlight the influence of the linkers connecting the polyacrylate main chains and the perfluorooctyl side chains, we compared two compounds, poly[2-(perfluorooctyl)ethyl] acrylate $\left(\mathrm{PFA}-\mathrm{C}_{8}\right)$ and poly\{2-[(perfluorooctylethyl) carbamate]ethyl acrylate $\left(\mathrm{PFAUr}-\mathrm{C}_{8}\right)$. Based on the reported thermotropic phase transition temperatures $[18,19]$ of unhydrated, dry PFA- $\mathrm{C}_{8}$ and PFAUr- $\mathrm{C}_{8}$, we studied these samples at several temperatures between $25^{\circ} \mathrm{C}$ and $90{ }^{\circ} \mathrm{C}$ to investigate their different phases.

\section{Materials and methods}

\section{Materials and sample preparation}

AK-225 (Asahi Glass Co., Tokyo, Japan), a fluorinecontaining solvent (mixture of 1,1-dichloro-2,2,3,3,3-pentafluoropropane and 1,3-dichloro-1,1,2,2,3-pentafluoropropane), was used as received. PFA- $\mathrm{C}_{8}$ [numberaverage molecular weight $(\mathrm{Mn}): 14.4 \mathrm{kD}$; polydispersity index: 1.56$]$ and PFAUr- $\mathrm{C}_{8}[\mathrm{Mn}: 6.3 \mathrm{kD}$; polydispersity index: 1.48 ] were prepared according to previously reported synthesis methods $[12,18]$. PFA- $\mathrm{C}_{8}$ and PFAUr- $\mathrm{C}_{8}$ films were prepared by casting polymer solutions in AK-225 $(40 \mathrm{mg} / \mathrm{mL})$ at room temperature onto rectangular silicon (111) wafers $\left(55 \times 25 \mathrm{~mm}^{2}\right)$ with native oxide (SUMCO, Japan) [13]. The silicon substrates were cleaned in advance using a modified RCA cleaning method [26]. The PFA- $\mathrm{C}_{8}$ and PFAUr- $\mathrm{C}_{8}$ films were thermally annealed for $24 \mathrm{~h}$ at $74{ }^{\circ} \mathrm{C}$ and $79^{\circ} \mathrm{C}$, respectively.

\section{Specular and off-specular neutron scattering}

Specular and off-specular neutron scattering experiments were carried out at beamline D16 of the Institut LaueLangevin (Grenoble, France) [21, 24]. As shown in Fig. 1b, the incoming neutron beam reached the sample through the aluminum window of the sample chamber, while the incident angle $\Omega$ was adjusted by a rotational stage. Each sample was kept in the sample chamber set to the temperature and osmotic pressure for more than $1 \mathrm{~h}$ prior to the measurement to establish thermal equilibrium between the sample and its environment. This set-up enables the fine adjustment of the chemical potential of water and hence the osmotic pressure from $\Pi_{\mathrm{H} 2 \mathrm{O}}=0 \mathrm{~Pa}$ to $\sim 10^{8} \mathrm{~Pa}$ according to the van't Hoff law, $\Pi_{\mathrm{H} 2 \mathrm{O}}=-\frac{k_{\mathrm{B}} T}{V_{\mathrm{w}}} \ln (R . H$.$) , where V_{\mathrm{w}}$ is the molecular volume of water, $k_{\mathrm{B}}$ is the Boltzmann constant, and $T$ is the sample temperature. Moreover, $h_{\text {rel }}$ is the relative humidity in the sample chamber and is defined by the following equation: $h_{\text {rel }}=p\left(T_{R}\right) p(T)$, where $p(T)$ and $p\left(T_{R}\right)$ denote the water vapor pressure at saturation in the sample and reservoir chambers, respectively. The equilibration of the system was experimentally confirmed, as the shape and position of the Bragg sheet remained constant throughout the rocking scan, both in angular and reciprocal coordinates. The reproducibility was checked by 
occasionally switching the relative humidity back and forth during the measurements.

The horizontal beam width was $3 \mathrm{~mm}$ and the vertical height was $20 \mathrm{~mm}$. The scattered beam was detected at exit angle $\Gamma$ by a position-sensitive ${ }^{3} \mathrm{He} 2 \mathrm{D}$ detector with $128 \times$ 128 channels. The raw detector readout was normalized to the intensity of the illuminated sample area, the direct beam, and the channel sensitivity. The $2 \mathrm{D}$ detector readout was integrated into a one-dimensional intensity projection as a function of $\Gamma$, yielding the intensity profile as a function of $\Omega$ and $\Gamma$. Owing to the planar sample geometry, the momentum transfers parallel and perpendicular to the substrate surface, $q_{\mathrm{z}}$ and $q_{\|}$, can be readily determined with the following equation: $q_{z}=\frac{2 \pi}{\lambda_{\mathrm{n}}}[\sin (\Gamma-\Omega)+\sin (\Omega)]$ and $q_{\|}=\frac{2 \pi}{\lambda_{\mathrm{n}}}[\cos (\Gamma-\Omega)-\cos (\Omega)]$, where $\lambda_{\mathrm{n}}$ is the wavelength of the monochromatic neutron beam $\left(\lambda_{\mathrm{n}}=4.52 \AA, \Delta \lambda_{\mathrm{n}} / \lambda_{\mathrm{n}}=\right.$ $1 \%)$ and $\Omega$ and $\Gamma$ are the incident and scattered angles, respectively.

\section{Results and discussion}

\section{Poorly hydrated PFA- $\mathrm{C}_{8}$ directly transitions into a disordered phase}

Figure 2 shows the scattering signals of PFA- $\mathrm{C}_{8}$ in angular coordinates ( $\Gamma$ vs. $\Omega$ ) measured at $T=25,74$, and $84{ }^{\circ} \mathrm{C}$ under different osmotic pressures $\Pi_{\mathrm{H} 2 \mathrm{O}}$. The scattering signals exhibited distinct Bragg sheets that were equidistantly separated, which suggested that PFA- $\mathrm{C}_{8}$ formed ordered periodic lamellae on the substrate. The positions of the Bragg sheets, which corresponded to the lamellar periodicity, did not shift significantly between $25^{\circ} \mathrm{C}$ and $74{ }^{\circ} \mathrm{C}$. More remarkably, the position of the Bragg sheets remained unchanged from low R.H. $\left(\Pi_{\mathrm{H} 2 \mathrm{O}} \sim 10^{8} \mathrm{~Pa}\right)$ to bulk water $\left(\Pi_{\mathrm{H} 2 \mathrm{O}} \sim 0 \mathrm{~Pa}\right)$, indicating that the acrylate groups were poorly hydrated. Volkov et al. [27] determined that the perfluorooctyl chains of PFA- $\mathrm{C}_{8}$ were hexagonally packed
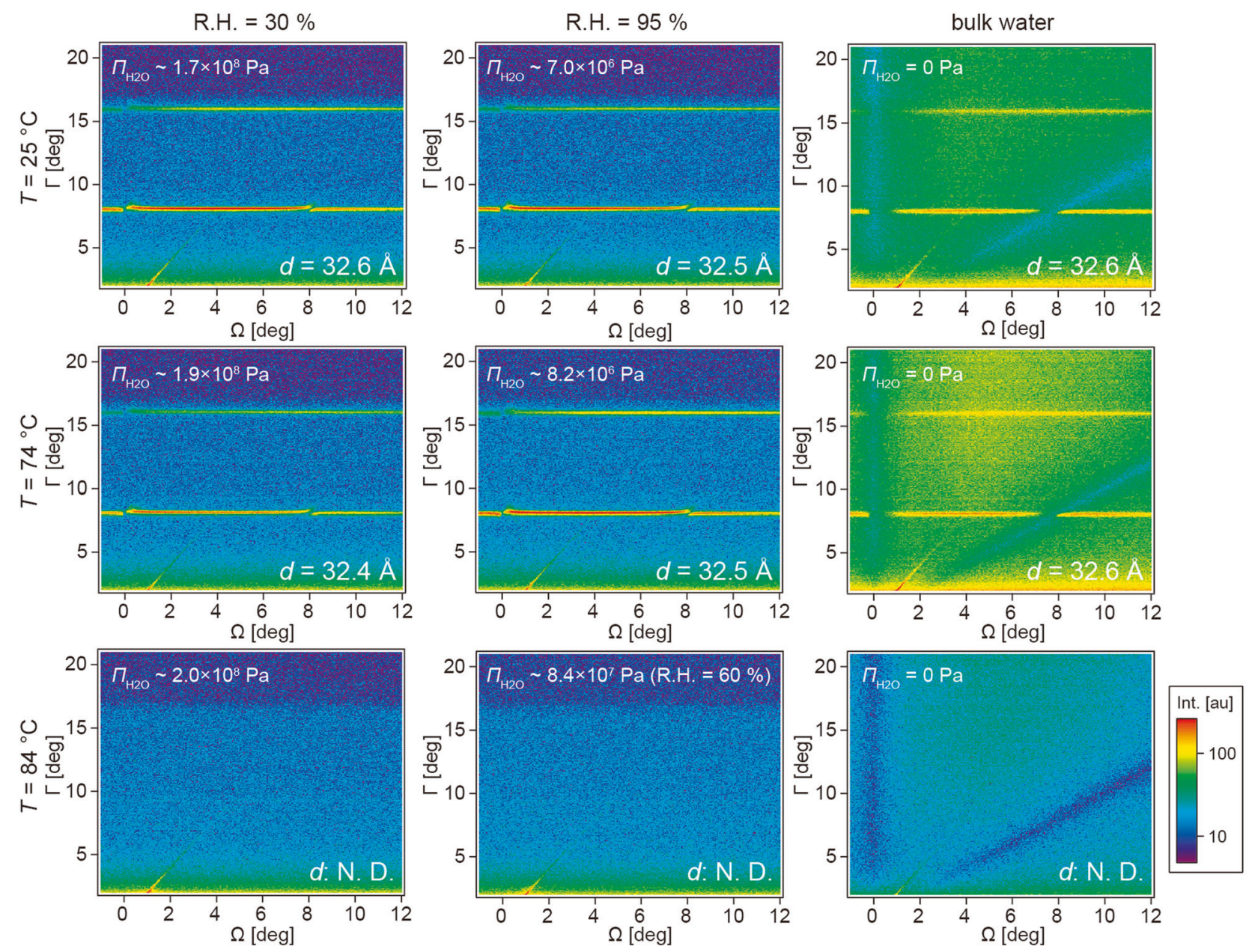

Fig. 2 Intensity profiles of PFA- $\mathrm{C}_{8}$ in angular coordinates measured at $T=25,74$, and $84{ }^{\circ} \mathrm{C}$ under different osmotic pressures $\Pi_{\mathrm{H} 2 \mathrm{O}}$. The scattering signals at $T=25$ and $74{ }^{\circ} \mathrm{C}$, characterized by equidistantly separated Bragg sheets, suggested that $\mathrm{PFA}-\mathrm{C}_{8}$ formed periodic

lamellae. The positions of the Bragg sheets did not shift significantly between $T=25$ and $74^{\circ} \mathrm{C}$, irrespective of the osmotic pressure $\Pi_{\mathrm{H} 2 \mathrm{O}}$. Bragg sheets were not detected at $T=84{ }^{\circ} \mathrm{C}$, suggesting that the system lost order 
(a)

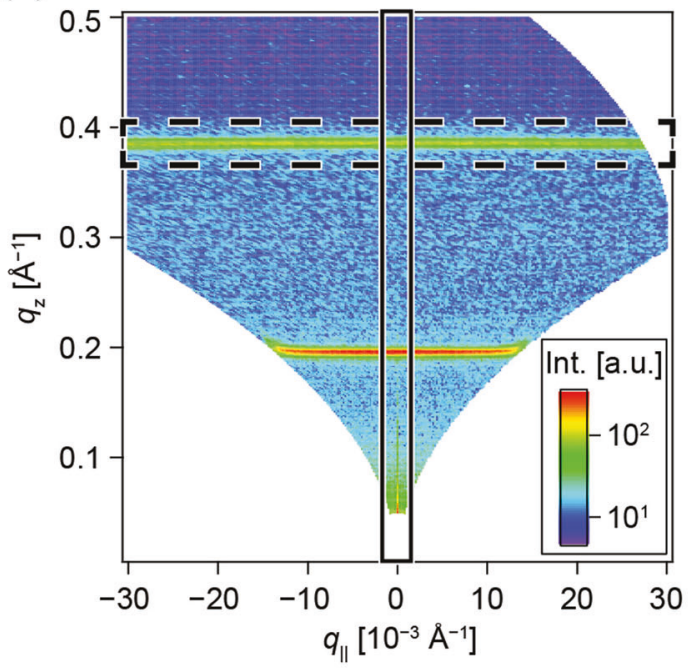

(c)

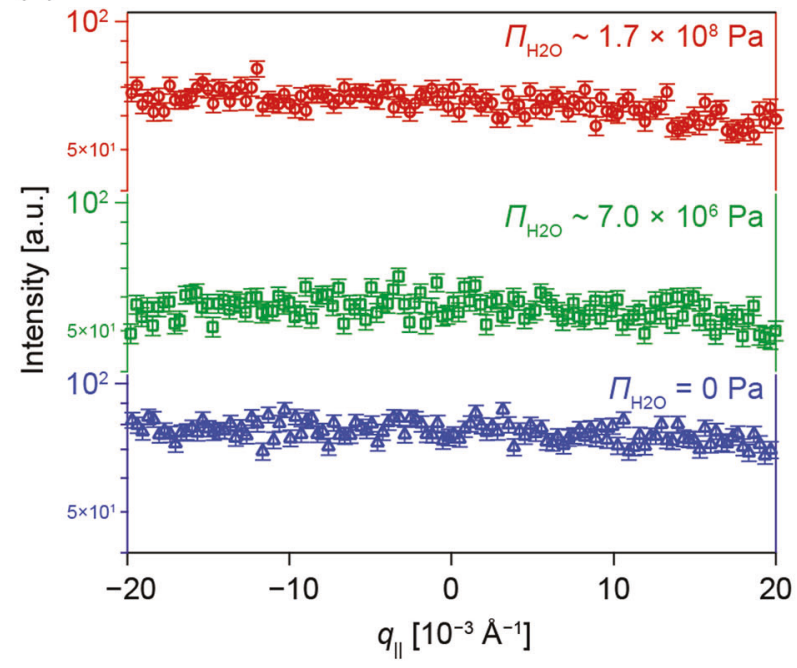

Fig. 3 a Scattering signals of PFA- $\mathrm{C}_{8}$ in reciprocal coordinates measured at $T=25^{\circ} \mathrm{C}$ and $\Pi_{\mathrm{H} 2 \mathrm{O}}=1.7 \times 10^{8} \mathrm{~Pa}$. The signals collected from the region surrounded by solid and broken lines indicate the specular line $\left(q_{\|}=0\right)$ and the second Bragg sheet, respectively. b1 Specular signals, obtained by integration along $q_{\|}=0$, of PFA-C 8 measured at $\Pi_{\mathrm{H} 2 \mathrm{O}}=1.7 \times 10^{8} \mathrm{~Pa}\left(\right.$ red), $7.0 \times 10^{6} \mathrm{~Pa}$ (green), and $0 \mathrm{~Pa}$

with a characteristic distance of $5.0 \AA\left(q \approx 12 \mathrm{~nm}^{-1}\right)$, which was attributed to the distance between helical fluorocarbon chains [3], using wide-angle X-ray diffraction (WAXD). At $T=84^{\circ} \mathrm{C}$, the characteristic Bragg sheets were absent. Previous dynamic viscoelasticity data indicated that significant mechanical absorption $\left(\Delta E_{\mathrm{a}}=1860 \mathrm{~kJ} / \mathrm{mol}\right)$ occurred at $77^{\circ} \mathrm{C}(350 \mathrm{~K})$ [28], and a differential scanning calorimetry heating scan revealed that an endothermic peak occurred at $74^{\circ} \mathrm{C}$, corresponding to a phase transition with an enthalpy $(\Delta H)$ of $\sim 160 \mathrm{~kJ} / \mathrm{mol}$ [18]. By using WAXD and polarized optical microscopy, this phase transition was determined to be directly lamellar to the disordered phase transition [18]. Therefore, the loss of the characteristic (b2)

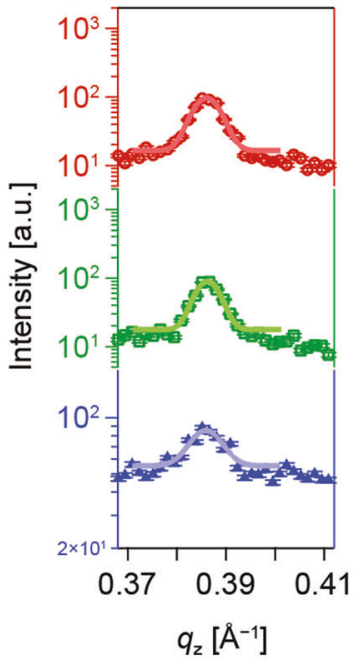

(d)

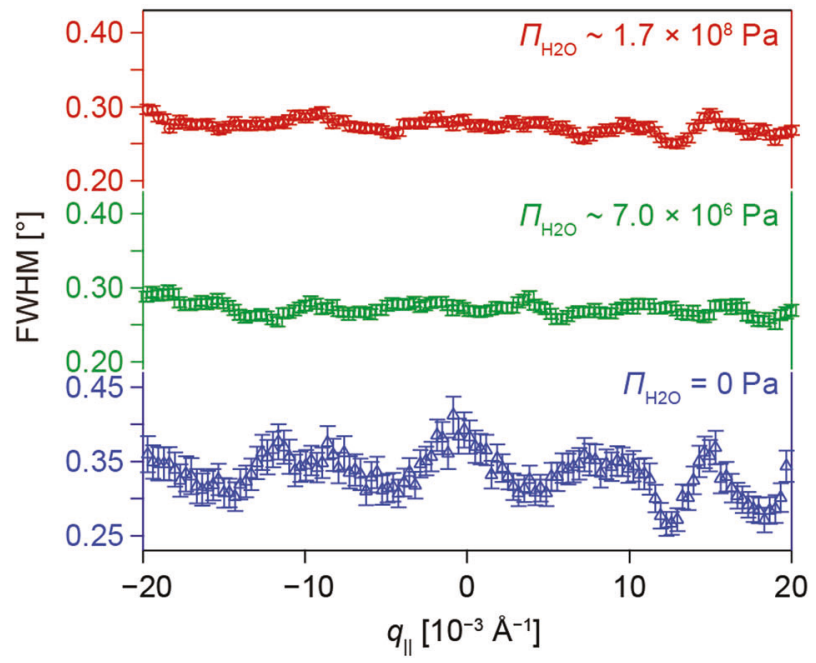

(blue). b2 Enlarged view of the 2nd Bragg peaks. The vertical correlation length $\xi_{0}$ is determined from the best fits (solid curves). c Intensity profile of the second Bragg sheets plotted as a function of $q_{\|}$. d Full width at half maximum (FWHM) profile of the second Bragg sheets plotted as a function of $q_{\|}$

Bragg sheets is in good agreement with previous studies on dry PFA-C $\mathrm{C}_{8}$ films.

\section{Hydration disturbs the interlayer correlation of PFA- $\mathrm{C}_{8}$}

Figure 3 a shows the scattering signals of PFA- $\mathrm{C}_{8}$ measured at $T=25^{\circ} \mathrm{C}$ and $\Pi_{\mathrm{H} 2 \mathrm{O}}=1.7 \times 10^{8} \mathrm{~Pa}$ in reciprocal coordinates, and Fig. 3b1 shows the integrated intensity along $q_{\|}=0$ plotted as a function of $q_{\mathrm{z}}$. As summarized in Table 1 , the periodicity of the PFA-C $\mathrm{C}_{8}$ lamellae at $\Pi_{\mathrm{H} 2 \mathrm{O}}=$ $1.7 \times 10^{8} \mathrm{~Pa}(32.6 \AA)$ and $\Pi_{\mathrm{H} 2 \mathrm{O}}=7.0 \times 10^{6} \mathrm{~Pa}(32.5 \AA)$, determined from the Bragg peak positions, was similar. Remarkably, the corresponding value measured in bulk 
Table 1 Summary of characteristic repeat distance $d$ and vertical correlation length $\xi_{0}$ of PFA- $\mathrm{C}_{8}$ lamellae at $T=25^{\circ} \mathrm{C}$

\begin{tabular}{lll}
\hline$\Pi_{\mathrm{H} 2 \mathrm{O}}[\mathrm{Pa}]$ & $d[\AA]$ & $\left.\xi_{0}[\AA]\right]$ \\
\hline $1.7 \times 10^{8}$ & $32.6 \pm 0.0$ & $299 \pm 1$ \\
$7.0 \times 10^{6}$ & $32.5 \pm 0.0$ & $331 \pm 1$ \\
0 & $32.6 \pm 0.0$ & $209 \pm 1$ \\
\hline
\end{tabular}

The uncertainty of each value is determined by the standard error of the fitting. For both $d$ and $\xi_{0}$, the difference for all possible combinations was significant $(p<0.01)$ from the $z$-test

water $\left(\Pi_{\mathrm{H} 2 \mathrm{O}}=0 \mathrm{~Pa}\right)$ was also similar $(32.6 \AA)$. As shown in Fig. $3 \mathrm{~b} 2$, the vertical correlation length $\xi_{0}$ was estimated from the full width at half maximum (FWHM) of the second Bragg peak according to the following equation: $\xi_{0}=2 / \mathrm{FWHM}_{0}$. The correlation length at low and high R. H. $\left(\xi_{0} \approx 300 \AA\right)$ indicated that the vertical correlation of the PFA- $\mathrm{C}_{8}$ lamellae reached a distance that was 10 times larger than the lamellar periodicity, implying that $\mathrm{PFA}-\mathrm{C}_{8}$ formed vertically correlated lamellae. Intriguingly, the correlation length decreased to $\approx 200 \AA$ when the sample was immersed in bulk water $\left(\Pi_{\mathrm{H} 2 \mathrm{O}}=0 \mathrm{~Pa}\right)$. The fact that the lamellar conformality was disturbed at $\Pi_{\mathrm{H} 2 \mathrm{O}}=0 \mathrm{~Pa}$ can be attributed to the higher fluctuation amplitude in the absence of external pressure. It is notable that the lamellar periodicity did not significantly change, even when the osmotic pressure was decreased by six orders of magnitude, which suggested that the PFA- $\mathrm{C}_{8}$ lamellae were poorly hydrated due to low water permeability. This watertight character of PFA- $\mathrm{C}_{8}$ is supported by previous WAXD data in which the perfluorooctyl chains of the PFA- $\mathrm{C}_{8}$ adopted highly ordered hexagonal packing [27]. The ordering of perfluorocarbon chains depends on the chain length. Liu et al. [18] showed that the contact angle hysteresis is smaller for the PFA- $\mathrm{C}_{8}$ surface than for the PFA- $\mathrm{C}_{6}$ surface because perfluorooctyl chains were of a higher order than the perfluorohexyl chains. As shown in Fig. 3c, the intensity profiles of the second Bragg sheets plotted as a function of $q_{\|}$did not contain any maxima at $q_{\|}=0$. Moreover, as presented in Fig. 3d, the FWHM profiles of the second Bragg sheets were almost flat with no minima. The emergence of significant diffuse scattering indicated that the small PFA- $\mathrm{C}_{8}$ lamellae were not aligned parallel to the substrate. This finding indicates that the treatment of PFA- $\mathrm{C}_{8}$ systems within the framework of discrete smectic Hamiltonians is invalid [25].

\section{PFAUr- $_{8}$ transitions to another lamellar phase}

The 2D scattering signals of $\mathrm{PFAUr} \mathrm{C}_{8}$ in reciprocal coordinates ( $\Gamma$ vs. $\Omega$ ) measured at $T=25,79$, and $89^{\circ} \mathrm{C}$ under different osmotic pressures $\Pi_{\mathrm{H} 2 \mathrm{O}}$ are shown in Fig. 4. Up to the third Bragg sheets were observed in the intensity profiles of PFAUr- $\mathrm{C}_{8}$, which were plotted along with the same angular coordinates as that of the PFA- $\mathrm{C}_{8}$. The characteristic repeat distance (lamellar periodicity) of PFAUr- $\mathrm{C}_{8}$ was $8 \AA$ larger than that of PFA- $\mathrm{C}_{8}$, which was attributed to the additional carbamate linker. Notably, the lamellar structure of PFAUr- $\mathrm{C}_{8}$ remained stable even in bulk water $\left(\Pi_{\mathrm{H} 2 \mathrm{O}}=0 \mathrm{~Pa}\right)$, similar to that of PFA-C $\mathrm{C}_{8}$. In marked contrast to PFA- $\mathrm{C}_{8}$, Bragg sheets were observed for PFAUr- $\mathrm{C}_{8}$ in bulk water at $T=89^{\circ} \mathrm{C}$, indicating that lamellar periodicity was maintained. A shift in the Bragg sheet position to a larger $\Gamma$ angle at $T=89^{\circ} \mathrm{C}$, corresponding to a decrease in lamellar periodicity by $4 \AA$, suggested that PFAUr- $\mathrm{C}_{8}$ transitioned into another lamellar phase. Therefore, the PFAUr- $\mathrm{C}_{8}$ lamellae are more stable than the PFA-C $\mathrm{C}_{8}$ lamellae, which can be explained by the additional enthalpic contribution to the total free energy of the system arising from the hydrogen bonds between the amide groups between the main backbone and the side chains [18].

\section{Hydration of PFAUr- $\mathrm{C}_{8}$ improves the interlayer correlation}

Fig. 5a shows a reciprocal space map of PFAUr- $\mathrm{C}_{8}$ measured at $T=25^{\circ} \mathrm{C}$ and $\Pi_{\mathrm{H} 2 \mathrm{O}}=1.7 \times 10^{8} \mathrm{~Pa}$, and Fig. $5 \mathrm{~b} 1$ shows the extracted specular signals. As summarized in Table 2, the periodicity of PFAUr- $\mathrm{C}_{8}$ lamellae at $\Pi_{\mathrm{H} 2 \mathrm{O}}=1.7 \times 10^{8} \mathrm{~Pa}(40.5$ $\AA$ ) and $\Pi_{\mathrm{H} 2 \mathrm{O}}=7.0 \times 10^{6} \mathrm{~Pa}(40.4 \AA)$ was similar. However, the periodicity of PFAUr- $\mathrm{C}_{8}$ measured in bulk water was slightly higher $(40.9 \AA)$, suggesting that the PFAUr- $\mathrm{C}_{8}$ lamellae were more hydrated than the PFA- $\mathrm{C}_{8}$ lamellae. It is plausible that PFAUr- $\mathrm{C}_{8}$ lamellae are more permeable to water, as a previous WAXD study showed a larger distortion of the hexagonal packing of perfluorooctyl chains in the PFAUr- $\mathrm{C}_{8}$ lamellae [27]. More remarkably, the vertical correlation length calculated from the FWHM $\left(\xi_{0}=388 \AA\right)$ was higher in bulk water than that at $\Pi_{\mathrm{H} 2 \mathrm{O}}=7.0 \times 10^{6} \mathrm{~Pa}$ $\left(\xi_{0}=330 \AA\right)$. This is an opposite trend from that of the watertight $\mathrm{PFA}-\mathrm{C}_{8}$ lamellae, whose lamellar conformality was disturbed at $\Pi_{\mathrm{H} 2 \mathrm{O}}=0 \mathrm{~Pa}$. This finding indicates that the hydration of PFAUr- $\mathrm{C}_{8}$ increases the lamellar periodicity and improves the interlamellar correlation in the direction perpendicular to the substrate. The intensity profiles of the second Bragg sheets plotted as a function of $q_{\|}$are presented in Fig. 5c. It is noted that the height of the second Bragg peak in bulk water $\left(\Pi_{\mathrm{H} 2 \mathrm{O}}=0 \mathrm{~Pa}\right)$ is lower than the humidity conditions because the contrast in the scattering length density is smaller. In stark contrast to PFA- $\mathrm{C}_{8}$, a broad maximum was observed at $q_{\|}=0$, suggesting that the fraction of PFAUr- $\mathrm{C}_{8}$ lamellae aligned parallel to the substrate was larger than that of PFA-C ${ }_{8}$. 

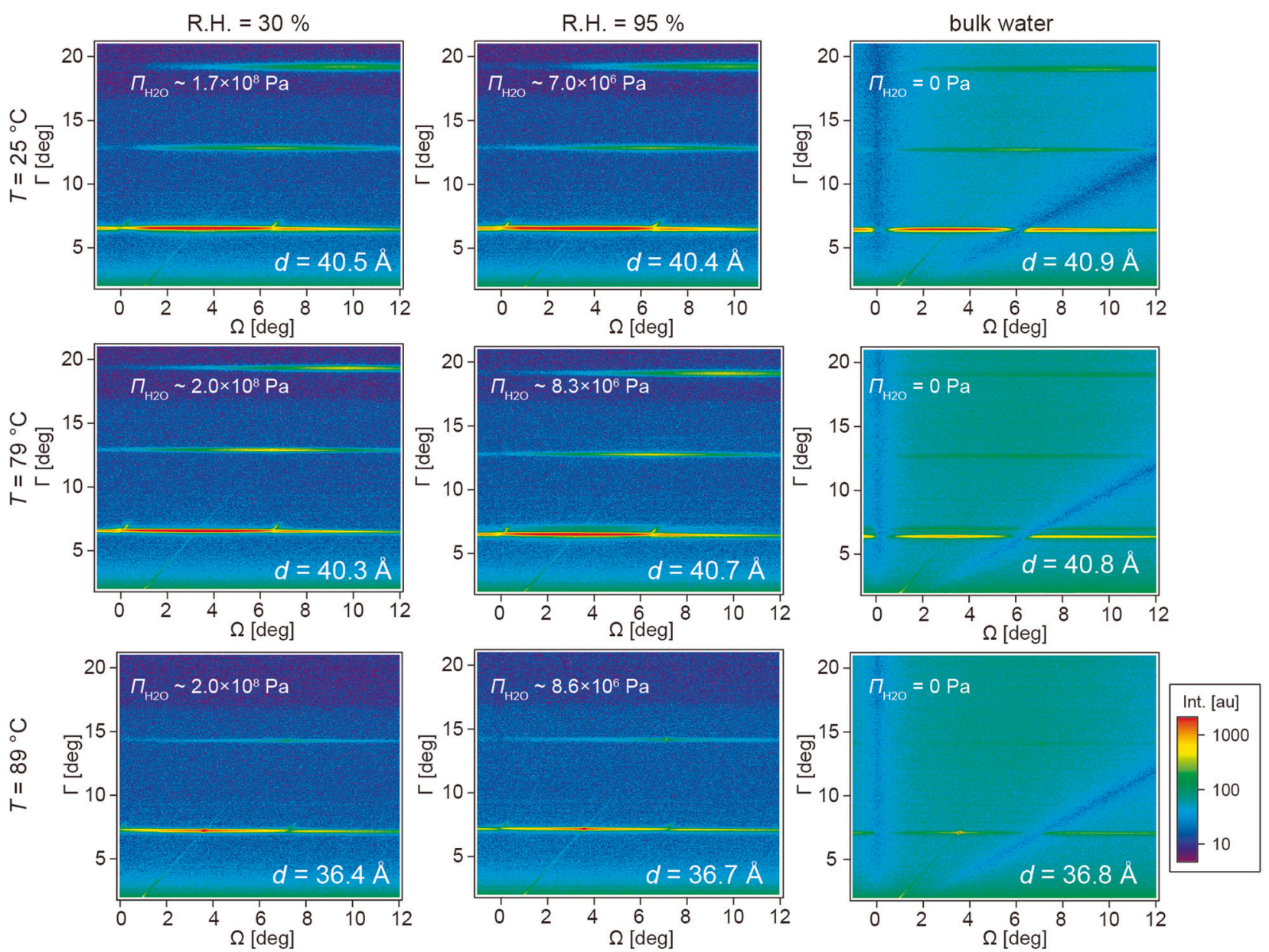

Fig. 4 Intensity profiles in angular coordinates of PFAUr- $\mathrm{C}_{8}$ measured at $T=25,79$, and $89^{\circ} \mathrm{C}$ under different osmotic pressures $\Pi_{\mathrm{H} 2 \mathrm{O}}$. In contrast to PFA- $\mathrm{C}_{8}$, clear Bragg sheets were observed at $T=89^{\circ} \mathrm{C}$.

\section{Differential effects of water on the thermotropic phases}

Our study provides insights into the effects of hydrating water on the structure and interlayer coupling of two polymers, $\mathrm{PFA}-\mathrm{C}_{8}$ and PFAUr- $\mathrm{C}_{8}$, which have been used as hydrophobic coating materials because of their high water contact angles $\left(\theta>120^{\circ}\right)$ [13]. In contrast, the studies of Volkov et al. [27, 28], Honda et al. [12, 14], and Liu et al. $[13,18]$ were performed under dry conditions, and the authors did not investigate the interactions of water molecules with these polymers. In this study, our specular and off-specular neutron scattering experiments were performed under humid conditions and in bulk water, and the results highlighted the differences between the two polymers.

The specular and off-specular neutron scattering results of PFA- $\mathrm{C}_{8}$ measured at $74{ }^{\circ} \mathrm{C}$ and $84{ }^{\circ} \mathrm{C}$ are presented in Figs. S1 and S2, respectively. The parameters extracted from the analyses are summarized in Tables $\mathrm{S} 1$ and $\mathrm{S} 2$. At $74{ }^{\circ} \mathrm{C}$, PFA- $\mathrm{C}_{8}$ exhibited the same trend as it did at $25^{\circ} \mathrm{C}$
Notably, the lamellar periodicity decreased by $\approx 4 \AA$ from that at the other temperatures

(Fig. S1). The lamellar periodicity remained almost constant, implying that the system remained in the same phase. Moreover, the vertical correlation length decreased in bulk water (Table S1), which can be attributed to the increase in fluctuation amplitude in the absence of external pressure $\left(\Pi_{\mathrm{H} 2 \mathrm{O}}=0 \mathrm{~Pa}\right)$. As shown in Fig. S2 and Table S2, PFA-C ${ }_{8}$ did not form an ordered structure at $T=84^{\circ} \mathrm{C}$, and this disordered phase was assigned by WAXD and polarized optical microscopy data [13]. The high mechanical absorption $(\Delta H=1860 \mathrm{~kJ} / \mathrm{mol})$ [27] and phase transition enthalpy ( $\Delta H=160 \mathrm{~kJ} / \mathrm{mol})$ [13] obtained for the dry PFA$\mathrm{C}_{8}$ films indicated that a direct transition occurred from the highly ordered smectic B phase to the disordered phase.

The specular and off-specular neutron scattering data for PFAUr- $\mathrm{C}_{8}$ at $79{ }^{\circ} \mathrm{C}$ and $89{ }^{\circ} \mathrm{C}$ are presented in Figs. S3 and $\mathrm{S} 4$, respectively. The parameters extracted from the analyses are presented in Tables S3 and S4. At $79^{\circ} \mathrm{C}$ (Fig. S3), the periodicity of PFAUr- $\mathrm{C}_{8}$ lamellae at $\Pi_{\mathrm{H} 2 \mathrm{O}}=8.3 \times 10^{6}$ $\mathrm{Pa}(40.7 \AA)$ was larger than that at $\Pi_{\mathrm{H} 2 \mathrm{O}}=2.0 \times 10^{8} \mathrm{~Pa}$ $(40.3 \AA)$, while the periodicity in bulk water $(40.8 \AA)$ was 


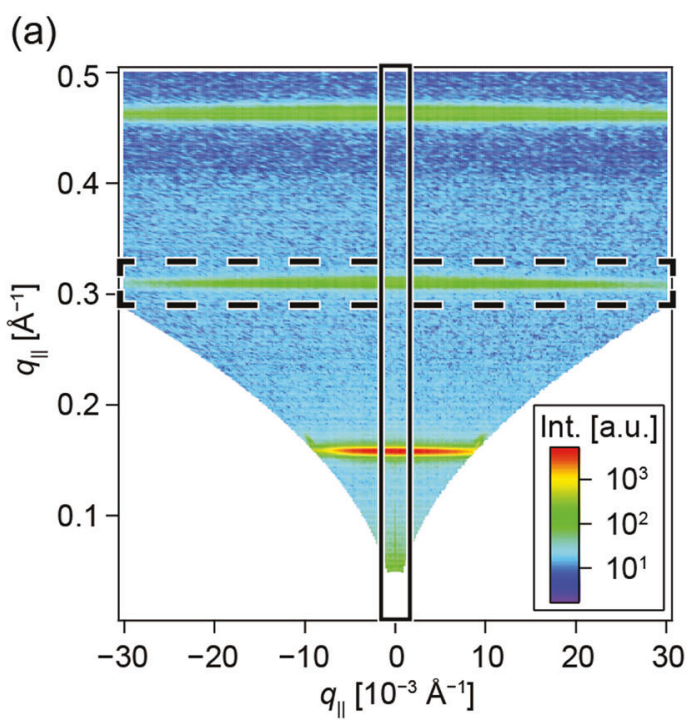

(c)

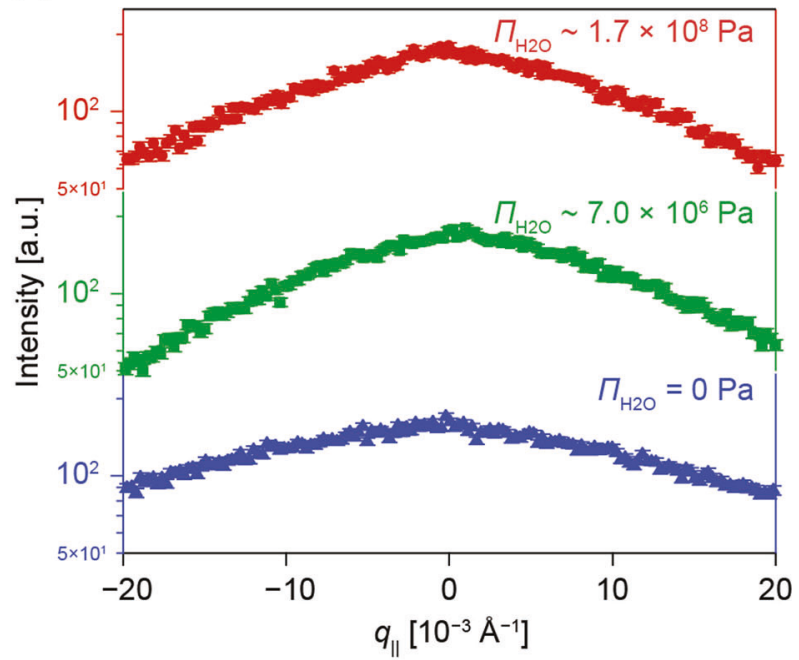

Fig. 5 a Reciprocal space map of PFAUr- $\mathrm{C}_{8}$ measured at $T=25^{\circ} \mathrm{C}$ and $\Pi_{\mathrm{H} 2 \mathrm{O}}=1.7 \times 10^{8} \mathrm{~Pa}$. The regions surrounded by the solid and broken lines indicate the specular line $\left(q_{\|}=0\right)$ and the second Bragg sheet, respectively. b1 Specular signals of PFAUr- $\mathrm{C}_{8}$ measured at $\Pi_{\mathrm{H} 2 \mathrm{O}}=1.7 \times 10^{8} \mathrm{~Pa}$ (red), $7.0 \times 10^{6} \mathrm{~Pa}$ (green), and $0 \mathrm{~Pa}$ (blue). b2

Table 2 Summary of characteristic repeat distance $d$ and vertical correlation length $\xi_{0}$ of PFAUr- $\mathrm{C}_{8}$ lamellae at $T=25^{\circ} \mathrm{C}$

\begin{tabular}{lll}
\hline$\Pi_{\mathrm{H} 2 \mathrm{O}}[\mathrm{Pa}]$ & $d[\AA]$ & $\xi_{0}[\AA]$ \\
\hline $1.7 \times 10^{8}$ & $40.5 \pm 0.0$ & $320 \pm 0$ \\
$7.0 \times 10^{6}$ & $40.4 \pm 0.0$ & $330 \pm 0$ \\
0 & $40.9 \pm 0.0$ & $388 \pm 0$ \\
\hline
\end{tabular}

The uncertainty of each value is determined by the standard error of the fitting. For both $d$ and $\xi_{0}$, the difference for all possible combinations was significant $(p<0.01)$ from the $z$-test

comparable to that under highly humid conditions. This finding suggests that the PFAUr- $\mathrm{C}_{8}$ lamellae were hydrated
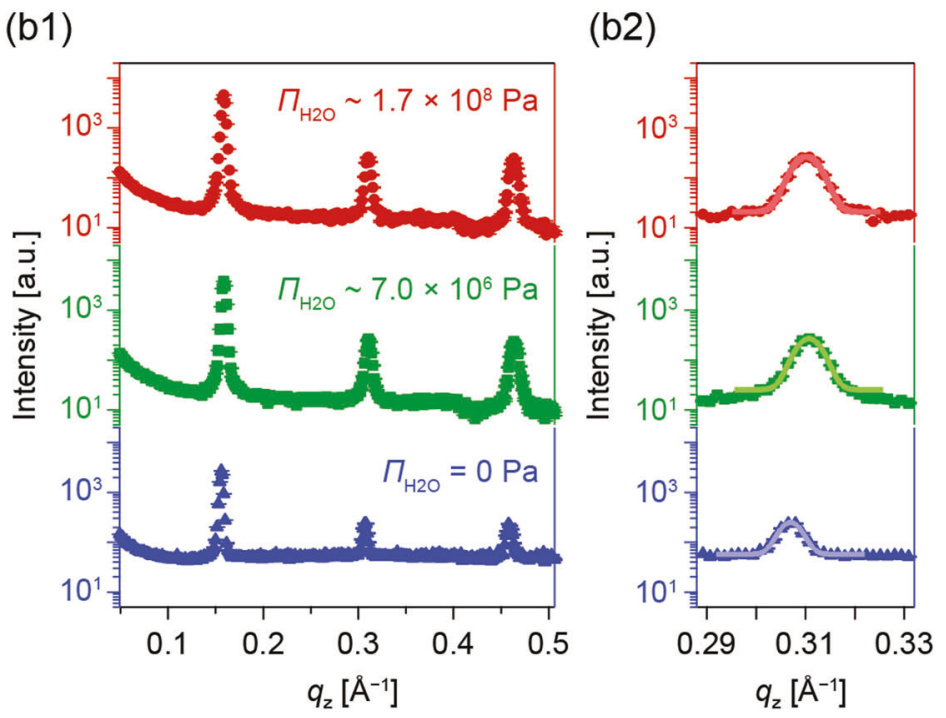

(d)

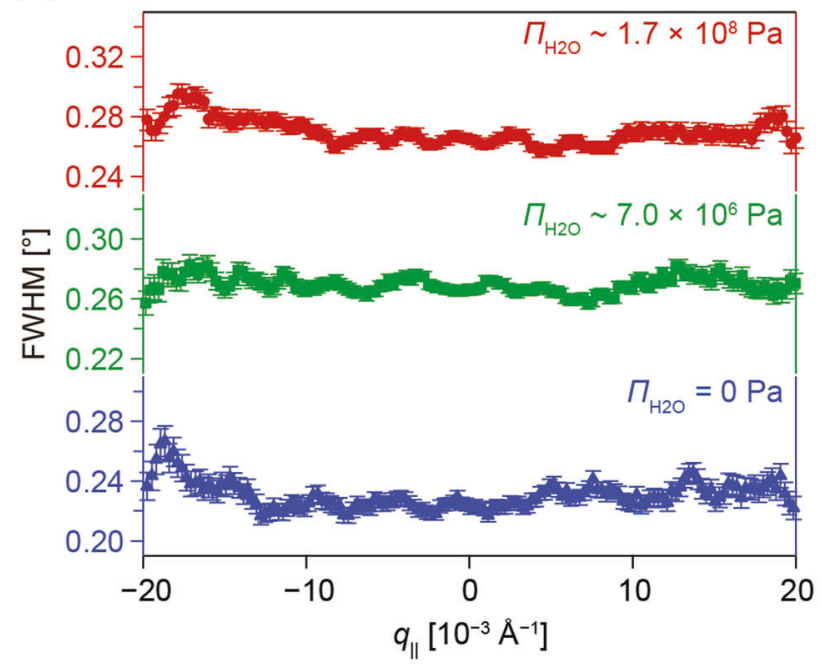

Enlarged view of the 2nd Bragg peaks. The vertical correlation length $\xi_{0}$ was determined from the best fits (solid curves). c Intensity profile of the second Bragg sheets plotted as a function of $q_{\|}$. $\mathbf{d}$ Full width at half maximum (FWHM) profile of the second Bragg sheets plotted as a function of $q_{\|}$

at $79^{\circ} \mathrm{C}$ at $\Pi_{\mathrm{H} 2 \mathrm{O}} \sim 10^{6} \mathrm{~Pa}$. This trend seems to follow the same tendency as was observed at $25^{\circ} \mathrm{C}$ : PFAUr- $\mathrm{C}_{8}$ lamellae are more permeable against water than $\mathrm{PFA}-\mathrm{C}_{8}$ lamellae due to the more distorted packing of the perfluorooctyl chains in PFAUr-C $\mathrm{C}_{8}$ [27]. Specifically, the increase in the chain mobility at $79^{\circ} \mathrm{C}$ enabled the hydration of the carbamate linker. Remarkably, PFAUr-C ${ }_{8}$ maintained its periodic lamellar structure at $89^{\circ} \mathrm{C}$ (Fig. S4). This observation is clearly different from that of the PFA- $\mathrm{C}_{8}$ lamellae, which lost their smectic order at $84^{\circ} \mathrm{C}$ (Fig. S2). As shown in Table $\mathrm{S} 4$, the lamellar periodicity of PFAUr$\mathrm{C}_{8}$ at $89^{\circ} \mathrm{C}$ was approximately $4 \AA$ smaller than those at $25^{\circ} \mathrm{C}$ (Table 2) and $79{ }^{\circ} \mathrm{C}$ (Table S3), irrespective of the 
osmotic pressure $\Pi_{\mathrm{H} 2 \mathrm{O}}$. A distinct change in the lamellar periodicity strongly suggests that the system transitions to another smectic phase. Previously, Liu et al. ${ }^{13,18}$ performed DSC experiments on dry PFAUr- $_{8}$ films and reported two endothermic peaks at $T^{*}=84^{\circ} \mathrm{C}$ and $143^{\circ} \mathrm{C}$. The former was attributed to the transition from smectic B to the partially interdigitated smectic A phase, while the latter was ascribed to the transition to the disordered phase. We found that the lamellar periodicity of hydrated PFAUr- $\mathrm{C}_{8}$ decreased by $4 \AA$, and more importantly, the vertical correlation length $\xi_{0}$ was approximately 10 times larger than the lamellar periodicity under all osmotic pressure conditions (Table S4), implying that PFAUr- $\mathrm{C}_{8}$ formed vertically correlated lamellae at $89^{\circ} \mathrm{C}$. Therefore, we excluded the scenario of chain interdigitation and interpreted that the decrease in periodicity by $4 \AA$ was caused by the melting of perfluorooctyl chains. This conclusion was suggested by the disappearance of the short-range order peak between $60^{\circ} \mathrm{C}$ and $90{ }^{\circ} \mathrm{C}$ in the grazing incidence-WAXD (GIWAXD) data of the dry PFAUr- $\mathrm{C}_{8}$ films [18]. We concluded that the transition to the smectic A phase is facilitated by hydration. In bulk water, the vertical correlation length $\xi_{0}$ was $355 \AA$ at $89^{\circ} \mathrm{C}$. This value was approximately $10-20 \%$ smaller than the values obtained at $89^{\circ} \mathrm{C}$ under different osmotic pressures $\left(467 \AA\right.$ at $2.0 \times 10^{8} \mathrm{~Pa}$ and $407 \AA$ at $8.6 \times 10^{6} \mathrm{~Pa}$ ), suggesting that unbound, bulk water molecules entered the space between the lamellae and weakened the interlayer coupling. Moreover, this value $\left(355 \AA\right.$ at $\left.89^{\circ} \mathrm{C}\right)$ was approximately $10 \%$ smaller than the values in bulk water measured at different temperatures $\left(388 \AA\right.$ at $25^{\circ} \mathrm{C}$ and $391 \AA$ at $79^{\circ} \mathrm{C}$ ). This tendency seems reasonable because PFAUr- $\mathrm{C}_{8}$ lamellae become permeable against water when the perfluorooctyl chains are disordered.

\section{Conclusions}

By using specular and off-specular neutron scattering, we have shown that the smectic lamellae of poly(perfluorooctyl acrylate) with a carbamate linker (PFAUr- $\mathrm{C}_{8}$ ) were hydrated. Remarkably, hydration was accompanied by a distinct increase in the vertical correlation length at $T=25^{\circ} \mathrm{C}$, indicating that the interlayer coupling in the direction perpendicular to the substrates was improved by hydration. Conversely, the smectic lamellae of poly[(perfluorooctyl) ethyl] acrylate without a carbamate linker $\left(\mathrm{PFA}-\mathrm{C}_{8}\right)$ were poorly hydrated, suggesting that the carbamate linker played a critical role in hydration, as supported by the FTIR data [13]. By comparing our data with that of a previous GIWAXD study of dry films, we postulated that hydrating water also modulated the thermotropic phases, although the dry films of both PFA- $\mathrm{C}_{8}$ and PFAUr- $\mathrm{C}_{8}$ are very hydrophobic (water contact angle $\theta>120^{\circ}$ ). Our data indicated that the hydrated PFAUr- $\mathrm{C}_{8}$ underwent a phase transition from the smectic $\mathrm{B}$ to smectic $\mathrm{A}$ phase, whereas dry PFAUr- $\mathrm{C}_{8}$ was reported to undergo a transition to the interdigitated smectic A phase. Because hydration facilitated by the linker modulates the self-assembled structure, interlayer coupling, and phase transition of apparently hydrophobic poly(perfluoroalkyl acrylate), water molecules can be used to optimize the self-assembly of hydrophobic liquid crystalline polymers.

Acknowledgements We thank the Institut Laue-Langevin for the neutron beam time. M.T. is thankful to JSPS KAKENHI (JP19H05719), Röntgen-Ångstrom Cluster and the Nakatani Foundation for support. A.T. acknowledges support from the JST-Mirai Program (Grant Number JPMJMI18A2), Japan. A.Y. thanks the German-Japanese University Network (HeKKSaGOn Alliance) and JSPS KAKENHI (JP19H05719, JP26800223 and JP16K05515) for support. We thank Edanz (https://jp.edanz.com/ac) for editing a draft of this manuscript.

\section{Compliance with ethical standards}

Conflict of interest The authors declare no competing interests.

Publisher's note Springer Nature remains neutral with regard to jurisdictional claims in published maps and institutional affiliations.

Open Access This article is licensed under a Creative Commons Attribution 4.0 International License, which permits use, sharing, adaptation, distribution and reproduction in any medium or format, as long as you give appropriate credit to the original author(s) and the source, provide a link to the Creative Commons license, and indicate if changes were made. The images or other third party material in this article are included in the article's Creative Commons license, unless indicated otherwise in a credit line to the material. If material is not included in the article's Creative Commons license and your intended use is not permitted by statutory regulation or exceeds the permitted use, you will need to obtain permission directly from the copyright holder. To view a copy of this license, visit http://creativecommons. org/licenses/by/4.0/.

\section{References}

1. Krafft MP, Riess JG. Chemistry, physical chemistry, and uses of molecular fluorocarbon-hydrocarbon diblocks, triblocks, and related compounds-unique "apolar" components for selfassembled colloid and interface engineering. Chem Rev 2009;109:1714-92.

2. Broniatowski M, Dynarowicz-Łątka P. Semifluorinated alkanes - Primitive surfactants of fascinating properties. Adv Colloid Interface Sci 2008;138:63-83.

3. Bunn CW, Howells ER. Structures of molecules and crystals of fluorocarbons. Nature 1954;174:549-51.

4. Krafft MP. Large organized surface domains self-assembled from nonpolar amphiphiles. Acc Chem Res 2012;45:514-24.

5. Veschgini M, Abuillan W, Inoue S, Yamamoto A, Mielke S, Liu $\mathrm{X}$, et al. Size, shape, and lateral correlation of highly uniform, mesoscopic, self-assembled domains of fluorocarbon-hydrocarbon diblocks at the air/water interface: a GISAXS study. ChemPhysChem 2017;18:2791-98. 
6. Hare EF, Shafrin EG, Zisman WA Properties of films of adsorbed fluorinated acids. J Phys Chem. 1954;58.

7. Pittman AG, Sharp DL, Ludwig BA. Polymers derived from fluoroketones. II. Wetting properties of fluoroalkyl acrylates and methacrylates. J Polym Sci Part A-1: Polym Chem 1968;6:1729-40.

8. Takahara A, Choi SB, Amaya N, Murata Y, Kajiyama T. Side chain effect on surface properties of poly(alkylfumarate) and poly (fluoroalkylfumarate). Rep. Prog Polym Phys Jpn 1987;30:187-90.

9. Ramharack R, Nguyen TH. Fluoropolymers of very low surface energies. J Polym Sci Part C: Polym Lett 1987;25:93-8.

10. Wang Z, Zuilhof H. Self-healing superhydrophobic fluoropolymer brushes as highly protein-repellent coatings. Langmuir 2016;32:6310-18.

11. Roussel F, Saidi S, Guittard F, Geribaldi S. Thermophysical properties of fluorinated acrylate homopolymers: mixing and phase separation. Eur Phys J E 2002;8:283-8.

12. Honda K, Morita M, Otsuka H, Takahara A. Molecular aggregation structure and surface properties of poly(fluoroalkyl acrylate) thin films. Macromolecules 2005;38:5699-705.

13. Liu Y, Higaki Y, Mukai M, Takahara A. Molecular aggregation structure and water repellency of Poly(perfluorohexyl acrylate) with a carbamate linkage. Polymer 2019;182:121846.

14. Honda K, Morita M, Sakata O, Sasaki S, Takahara A. Effect of surface molecular aggregation state and surface molecular motion on wetting behavior of water on poly(fluoroalkyl methacrylate) thin films. Macromolecules 2010;43:454-60.

15. Banerjee S, Tawade BV, Ladmiral V, Dupuy LX, MacDonald MP, Améduri B. Poly(fluoroacrylate)s with tunable surface hydrophobicity via radical copolymerization of 2,2,2-trifluoroethyl $\alpha$-fluoroacrylate and 2-(trifluoromethyl)acrylic acid. Polym Chem 2017;8:1978-88.

16. Corpart J-M, Girault S, Juhué D. Structure and surface properties of liquid crystalline fluoroalkyl polyacrylates: role of the spacer. Langmuir 2001;17:7237-44.

17. Ishige R, Shinohara T, White KL, Meskini A, Raihane M, Takahara $\mathrm{A}$, et al. Unique difference in transition temperature of two similar fluorinated side chain polymers forming hexatic smectic phase: Poly\{2-(perfluorooctyl)ethyl acrylate $\}$ and Poly\{2-(perfluorooctyl)ethyl vinyl ether\}. Macromolecules 2014;47:3860-70.
18. Liu Y, Higaki Y, Mukai M, Ohta N, Kabe T, Takahara A. Smectic ordered structure and water repellency of a poly(fluoroalkyl acrylate) with a carbamate linker. Polym J 2019;51:189-98.

19. Ishige R, Yamaguchi H, Shinohara T, Meskini A, Raihane M, Takahara A, et al. Structural analysis and surface wettability of a novel alternated vinylidene cyanide with fluorinated vinyl ether copolymer. Polym J 2013;45:1041-6.

20. Honda K, Yamamoto I, Morita M, Yamaguchi H, Arita H, Ishige $\mathrm{R}$, et al. Effect of $\alpha$-substituents on molecular motion and wetting behaviors of poly(fluoroalkyl acrylate) thin films with short fluoroalkyl side chains. Polymer 2014;55:6303-8.

21. Schneck E, Rehfeldt F, Oliveira RG, Gege C, Demé B, Tanaka M. Modulation of intermembrane interaction and bending rigidity of biomembrane models via carbohydrates investigated by specular and off-specular neutron scattering. Phys Rev E 2008;78:061924.

22. Schneck E, Oliveira RG, Rehfeldt F, Demé B, Brandenburg K, Seydel U, et al. Mechanical properties of interacting lipopolysaccharide membranes from bacteria mutants studied by specular and off-specular neutron scattering. Phys Rev E 2009;80:041929.

23. Schneck E, Demé B, Gege C, Tanaka M. Membrane adhesion via homophilic saccharide-saccharide interactions investigated by neutron scattering. Biophysical J 2011;100:2151-9.

24. Yamamoto A, Abuillan W, Burk AS, Körner A, Ries A, Werz DB, et al. Influence of length and conformation of saccharide head groups on the mechanics of glycolipid membranes: Unraveled by off-specular neutron scattering. The. J Chem Phys 2015; 142:154907.

25. Lipowsky R, Leibler S. Unbinding transitions of interacting membranes. Phys Rev Lett 1986;56:2541-4.

26. Kern W, Puotinen DA. Cleaning solutions based on hydrogen peroxide for use in silicon semiconductor technology. RCA Rev 1970;31:187-206.

27. Volkov VV, Platé NA, Takahara A, Kajiyama T, Amaya N, Murata Y. Aggregation state and mesophase structure of combshaped polymers with fluorocarbon side groups. Polymer 1992;33:1316-20.

28. Volkov VV, Fadeev AG, Plate NA, Amaya N, Murata Y, Takanara A, et al. Effect of thermal molecular motion on pervaporation behavior of comb-shaped polymers with fluorocarbon side groups. Polym Bull 1994;32:193-200. 